\title{
Caracterização das empresas produtoras de pellets em Santa Catarina
}

\author{
Characterization of pellet producing companies in Santa Catarina \\ Daniela Letícia Nones, Martha Andreia Brand*, Ana Carolina Battaglin \\ Universidade do Estado de Santa Catarina, Lages, SC. Brasil. *Autor para correspondência: martha.brand@udesc.br
}

\begin{abstract}
RESUMO
O objetivo deste trabalho foi obter uma visão geral das empresas produtoras de pellets provenientes de biomassa residual florestal de Santa Catarina, abordando características relacionadas à matéria-prima, aos equipamentos utilizados, custos de produção, entre outros atributos que influenciam na dinâmica do setor do estado. Foi realizada a aplicação de questionários in loco para cada empresa participante do estudo. As empresas avaliadas iniciaram suas atividades recentemente, a matéria-prima é a maravalha de Pinus spp. com umidade entre 8 e 10\% e os equipamentos para peletização são adaptados para biomassa, prejudicando o processo. O mercado interno absorve toda a produção e foi destacado que a criação de uma normatização brasileira seria positiva, principalmente no que diz respeito às classes de qualidade dos pellets. Também foi observada a falta de interação entre as três empresas produtoras de pellets, o que prejudica o crescimento da cadeia produtiva de pellets em Santa Catarina.
\end{abstract}

PALAVRAS-CHAVE: organização setorial, energia de biomassa, compactados de madeira.

\begin{abstract}
The objective of this work was to obtain an overview of companies producing pellets from forest residual biomass of Santa Catarina, addressing characteristics related to raw material, equipment used, production costs, among other attributes that influence the dynamics of the state sector. Questionnaires were applied to each company participating in the study. The evaluated companies started their activities recently, the raw material is the wood of Pinus spp. With humidity between 8 and $10 \%$ and the equipment for pelletizing are adapted to biomass, damaging the process. The domestic market absorbed all the production and it was emphasized that the creation of a Brazilian standardization would be positive, especially with respect to the grades of pellet quality. It was also observed the lack of interaction between the three companies producing pellets, which hinders the growth of the pellet production chain in Santa Catarina.
\end{abstract}

KEYWORDS: sectoral organization, biomass energy, compacte.

\section{INTRODUÇÃO}

A questão energética mundial está em foco nos últimos anos, principalmente em relação à busca de fontes alternativas de energia que possam diminuir o consumo de combustíveis fósseis e amenizar os impactos gerados ao meio ambiente.

A partir do momento em que se percebeu que os recursos são finitos, que o consumo cresceu além da capacidade de fornecimento de cada época e que os impactos ambientais se tornaram foco de discussões e preocupações, as questões energéticas também tomaram outro rumo. Nos últimos anos, o foco de pesquisa do tema "energia" está centrado no apoio e desenvolvimento do uso de fontes alternativas, preferencialmente menos poluentes e de processos mais eficientes e menos impactantes, sem esquecer o custo econômico e social dos empreendimentos (BRAND \& COSTA 2007).

Neste sentido, a biomassa residual florestal surge como uma ótima alternativa, pois além de ser renovável, a sua utilização como fonte de energia diminui os impactos ambientais gerados com a destinação incorreta dos resíduos. Santa Catarina produz grandes quantidades de resíduos provenientes das atividades florestais e vêm buscando utilizar de maneira mais eficiente estes resíduos, com o uso na compactação (produção de pellets e briquetes). A compactação visa melhorar o aproveitamento do potencial energético destes resíduos, aumentando o poder calorífico do produto compactado em relação ao resíduo in natura.

Além disso, com o encarecimento dos combustíveis tradicionais (além dos seus impactos ambientais) 
e os custos decrescentes da biomassa com altas taxas de produção por hectare, é muito provável que no curto prazo exista maior viabilidade comercial na fabricação de pellets de madeira no Brasil (ESCOBAR \& COELHO 2014).

O mercado de pellets de madeira está passando por um rápido desenvolvimento: em 2000, a produção mundial anual estava em torno de 1,8 milhão de toneladas, aumentando para 24,5 milhões de toneladas em 2013 (CALDERON et al. 2014). A capacidade de produção instalada também foi expandida em todo o mundo para cerca de 42 milhões de toneladas em 2012 (CALDERON et al. 2013). Os países como maior aumento na capacidade de produção de pellets foram: EUA, Canadá e Rússia, que são também os maiores exportadores de pellets de madeira, principalmente de uso industrial (CALDERON et al. 2014).

Em Santa Catarina, a cadeia produtiva de pellets tem sua formação recente no estado e é composta pelos fornecedores de insumos (equipamentos e matéria-prima), produtores de pellets, consumidores de pellets, ambiente institucional e organizacional (NONES 2014). Também levando em consideração que a cadeia de produção é definida a partir de um determinado produto final (BATALHA \& SILVA 2001), se tem as empresas produtoras de pellets com um dos principais elos desta cadeia de produção.

No entanto, são escassos os dados sobre este setor produtivo no estado, indicando assim a importância de estudos que enfatizem como ocorrem as relações entre os atores envolvidos nesta cadeia produtiva. Sendo assim, o objetivo deste trabalho foi obter uma visão geral das empresas produtoras de pellets, provenientes de biomassa residual florestal em Santa Catarina, abordando características que influenciam na dinâmica do setor.

\section{MATERIAL E MÉTODOS}

O estudo foi realizado em Santa Catarina, durante os meses de julho e agosto de 2013. O enfoque desta pesquisa foi qualitativo, onde se utilizou a coleta de dados por observação semi-estruturada, utilizando-se um questionário e entrevistas abertas, juntamente com a avaliação de experiências pessoais e inspeção da história de vida dos empresários. Além disso, a pesquisa foi conduzida no ambiente dos entrevistados (natural) sem a manipulação de variáveis. O objetivo desta metodologia de análise foi de contextualização do ambiente de pesquisa (SAMPIERI et al. 2006).

Além do enfoque ter sido qualitativo, o alcance da pesquisa proposto foi o Descritivo. Neste alcance se buscou especificar as propriedades, as características, os perfis importantes das pessoas e das empresas analisadas, avaliando-se e coletando os dados sobre diversos aspectos, dimensões e componentes das empresas produtoras de pellets de Santa Catarina. Portanto, o estudo foi centrado na coleta dos dados objetivando descrever a situação em que se encontrava a cadeia produtiva de compactados no momento da pesquisa, de modo a entender a dinâmica do setor.

A aplicação dos questionários foi realizada durante visitas in loco (no ambiente dos entrevistados) aos representantes das empresas produtoras de pellets. Os representantes foram os proprietários das empresas ou responsáveis diretamente envolvidos com a produção de pellets, para que as respostas fossem bem específicas.

O questionário contou com 12 perguntas abertas, abrangendo temas sobre a localização da empresa, início da atuação na área de peletização, matéria-prima utilizada (fornecedores, preço pago, utilização de pré-tratamento), características do equipamento utilizado na peletização, custos de produção e quantidade produzida por mês. As empresas também responderam perguntas sobre seus clientes, com o objetivo de saber qual a utilização final dos pellets, como era realizada a venda do produto e se os compradores exigiam um relatório de qualidade do produto, além do preço de venda dos pellets. Além disso, as empresas foram perguntadas sobre as perspectivas de crescimento para o setor no estado.

Todas as empresas produtoras de pellets do estado participaram do estudo, totalizando três empresas. Portanto, o trabalho se caracterizou como um censo no setor estadual. Vale ressaltar que em 2016, GARCIA et al. (2017) realizaram censo nas empresas produtoras de pellets no Brasil, com o mesmo enfoque deste trabalho, e constaram que o número de indústrias peletizadoras de biomassa para energia totalizava 13 unidades fabris no país.

Não foi aplicada nenhuma ferramenta estatística para a análise dos resultados.

\section{RESULTADOS E DISCUSSÃO}

Foi identificado que em Santa Catarina existem três empresas que atuam na produção de pellets, situadas em Curitibanos, Benedito Novo e Campo Alegre. As três empresas foram avaliadas neste estudo.

Todas as empresas são consideradas jovens no ramo de peletização, sendo que duas delas iniciaram 
suas atividades no ano de 2007 e outra em 2011. Um estudo realizado pela Embrapa Agroenergia, em 2012, com 14 empresas produtoras de pellets e briquetes no Brasil, revelou que $72 \%$ destas foram criadas a partir do ano 2000 e que surgiram para suprir a crescente demanda por fontes de energia alternativas ao petróleo e à lenha. O estudo também mostrou que $80 \%$ das empresas analisadas situam-se nos estados de São Paulo, Paraná e Santa Catarina (DIAS et al. 2012). As empresas de briquetes são as mais antigas, mas muitas encerraram suas atividades nos últimos anos, inclusive no Estado de Santa Catarina.

Mais recentemente, GARCIA et al. (2017) constaram que existem, no Brasil, 13 plantas industriais de pellets e que estas são relativamente jovens, tendo sido criadas a partir de 2004 e $69 \%$ delas surgiram depois de 2012. Os autores concluíram, portanto, que as empresas têm pouco mais de 12 anos de atuação no mercado, representado a realidade de Santa Catarina.

KRISTÖFEL et al. (2016) em um estudo realizado na Europa também destacaram que o mercado de pellets ainda é imaturo e volátil, tendo menor capacidade de equilibrar o impacto das turbulências do mercado do que mercados maiores e mais maduros.

Em relação à matéria-prima, as três empresas catarinenses utilizam resíduos florestais na forma de maravalha, somente de madeira de Pinus spp. Esta também é a realidade encontrada nas outras empresas do Brasil, pois de acordo com o estudo de GARCIA et al. (2017) todas as empresas utilizam os resíduos de Pinus das indústrias madeireiras como principal matéria-prima do processo de peletização.

$\mathrm{Na}$ Europa, o mercado de pellets de madeira está intimamente ligado ao mercado de madeira: cerca de $90 \%$ da matéria-prima para peletização é fornecida como resíduos de serrarias (KRISTÖFEL et al. 2016).

As empresas de Santa Catarina não possuem sistema de secadores, por esse motivo têm preferência pela compra do resíduo seco, com umidade entre 8 a 10\%. Segundo NIEDZIÓŁKA et al. (2015), a biomassa destinada à compactação deve estar em um intervalo de umidade de 8 a $15 \%$. Valores de umidade acima de $15 \%$ contribuem para a quebra dos compactados e a degradação biológica durante o transporte e armazenamento, sendo ainda a principal causa da diminuição da qualidade dos pellets e do seu poder calorífico líquido.

Dessa forma, as fontes de matéria-prima são restritas, sendo geralmente indústrias de esquadrias de madeira, indústrias moveleiras e serrarias, que produzem o resíduo na umidade desejada. De maneira geral, os custos de produção em relação à matéria-prima correspondem a aproximadamente $60 \mathrm{a} 70 \%$ do total. Os outros custos estão relacionados à pagamento de funcionários, aluguel, energia elétrica, entre outros.

Observa-se que as empresas produtoras de pellets estão localizadas próximas aos seus fornecedores de matéria-prima, minimizando os custos com transporte, caracterizando-se como uma vantagem econômica. Em contrapartida, as empresas acabam dependendo de um ou dois fornecedores regionais, o que pode gerar gargalos na produção, caso a matéria-prima não seja disponibilizada regularmente.

Um fator que pode colaborar para diminuir esta dependência foi citado por NONES et al. (2017) em um estudo sobre biomassa residual florestal e agrícola em Santa Catarina. Neste estudo, os autores afirmaram que algumas empresas se especializaram na compra e no tratamento de resíduos florestais, com o intuito de revender este material para empresas que utilizam biomassa como fonte energética. Ainda de acordo com os autores, estas empresas têm relatado que a distância viável para o transporte de biomassa é de $80 \mathrm{~km}$, podendo aumentar quando o valor de mercado do resíduo estiver em alta.

A média da produção mensal de cada uma das empresas é de aproximadamente 300 toneladas, podendo até duplicar na época do inverno, quando a demanda pelo produto cresce consideravelmente. A produção é totalmente absorvida pelo mercado interno e os principais compradores são do setor de serviços (hotéis, motéis, academias e pizzarias) e do setor industrial. Além de atender grande parte da demanda do estado, as empresas enviam o pellet catarinense para outras regiões, principalmente Paraná e Rio Grande do Sul.

A utilização de pellets de madeira tem sido impulsionada principalmente pela demanda industrial para co-queima e produção combinada de calor e energia (cogeração). No entanto, há também um interesse crescente em pellets de madeira de alta qualidade para usuários de pequena e média escala no setor de aquecimento residencial (KRISTÖFEL et al. 2016).

A venda e a distribuição são realizadas de forma direta, onde as próprias empresas negociam com os compradores. A forma de armazenamento para comercialização também é similar nas três empresas pesquisadas. O pellet pode ser comprado em sacos plásticos de 15 a $25 \mathrm{Kg}$ ou big bags de 750 a $1300 \mathrm{Kg}$. Nesta etapa do processo foi identificada uma interação entre duas empresas. Por atuarem em regiões distintas, quando surge um cliente fora do seu raio de atuação, uma empresa repassa para a outra, e vice- 
versa. Isso ocorre para que o custo de transporte da entrega do produto não seja encarecido, e a empresa possa oferecer um preço mais atrativo ao cliente.

Os equipamentos utilizados pelas empresas que produzem pellets em Santa Catarina não são específicos para a peletização de biomassa. As três empresas pesquisadas utilizam equipamentos para peletização de ração animal adaptadas para peletizar biomassa florestal. Na maioria dos casos, apenas a matriz peletizadora (peça responsável por dar formato ao pellet e que sofre o maior atrito com a matériaprima) é importada e o restante do equipamento é nacional.

Os proprietários reconhecem que este não é o tipo de equipamento ideal, principalmente no que diz respeito à manutenção da máquina e à qualidade final do produto, que sofre influência direta da pressão utilizada para compactação. Além disso, a produtividade final também é prejudicada, visto que o equipamento precisa parar de funcionar para manutenção das peças com frequência.

Quando se trata de exportar a produção, os entrevistados contam que já pensaram nessa possibilidade, mas que ainda existem alguns entraves. Um exemplo é a adequação às normas técnicas internacionais exigidas por alguns países, que possuem suas próprias regras para produção e qualidade final dos pellets. Esta não é apenas a realidade catarinense, mas também brasileira. No estudo realizado pela Embrapa Agroenergia (DIAS et al. 2012), a inexistência de laboratórios para análises técnicas dos briquetes e pellets no Brasil e a falta de conhecimento sobre as normas vigentes no mercado externo foram frequentemente citadas pelos produtores como obstáculos à exportação de produtos.

Os grandes consumidores europeus como a Itália e o Reino Unido, por exemplo, exigem conformidade dos pellets com a norma ISO 17225-2 (CEN 2014), com critérios rígidos para a qualidade dos pellets, sobretudo tipo A1 para uso residencial (GARCIA et al. 2017).

SPANHOL et al. (2015) realizaram um estudo que comparou a qualidade dos pellets de biomassa florestal residual de Pinus spp., provenientes da cadeia produtiva de Santa Catarina, com os critérios de qualidade das normas internacionais existentes. Os autores concluíram que os valores médios das propriedades dos pellets catarinenses atenderam plenamente as normas alemã e austríaca e algumas classes de qualidade das normas sueca, e da ISO 17225-2, possibilitando o uso dos pellets no setor industrial e de serviços.

No Brasil, a produção de pellets não possui nenhuma regulamentação, não existe um selo de qualidade, por exemplo. A qualidade dos pellets está relacionada ao teor de umidade, teor de finos, durabilidade, entre outros, além do poder calorífico e teor de cinzas. As três empresas consideram que a criação de uma normatização seria algo positivo, principalmente no que diz respeito às classes de qualidade do produto final. Cada classe de qualidade é destinada a um tipo de uso (doméstico, serviços ou industrial) e possui propriedades diferentes, sendo sempre a de uso doméstico mais restritiva em relação ao teor de cinzas, teor de umidade e poder calorífico.

Outro entrave para exportação é a quantidade dos pellets produzida no estado de Santa Catarina, que é pequena em relação às demandas para exportação. As três empresas pesquisadas, em conjunto, produzem aproximadamente 900 toneladas ao mês, o que não seria suficiente para exportar sem deixar de atender o mercado interno. Segundo GARCIA et al. (2017), a maior parte das indústrias peletizadoras do Brasil (92,3\%) é de pequeno porte (com produção estimada de até 8 mil toneladas por ano) e que somente uma indústria brasileira $(7,69 \%)$ tem produção anual superior a 30 mil toneladas por ano.

A ideia da exportação de pellets da cadeia produtiva de Santa Catarina precisa ser amadurecida e cercada de estudos de logística, visando principalmente o aumento de produção e adequação às normas estrangeiras.

Quando se trata das características do produto, os clientes não fazem questão de um laudo de qualidade do produto final. O interesse é apenas sobre o poder calorífico do material (quantidade de calor que o produto irá gerar) e o teor de cinzas, que está relacionado à produção de resíduos e, consequentemente, à frequência em que a caldeira (queimador) deverá ser limpa.

A pesquisa destaca ainda que a falta de conhecimento sobre o pellet por parte da população em geral é grande. Muitas pessoas não sabem o que são pellets, do que são produzidos e qual a sua utilidade prática. $\mathrm{Ou}$, em alguns casos, já tiveram contato com o produto, porém os resultados da utilização não foram satisfatórios, tendo em vista que o produto não era adequado ao uso ao qual se destinou. Esse fato é apontado pelos representantes das empresas como uma grande dificuldade para à expansão dos negócios e aumento do número de clientes. Em seu estudo, GARCIA et al. (2017), afirmaram que é importante relatar que a indústria brasileira de pellets ainda é muito jovem e que é necessário mais tempo para que empresários, consumidores e a sociedade em geral conheçam as vantagens econômicas e ambientais obtidas com a utilização dos pellets de madeira. 
Além disso, foi possível perceber que não existe um relacionamento entre as empresas produtoras, ou seja, cada uma trabalha por si, visando seu próprio crescimento. É fundamental que as empresas criem algum elo para intercâmbio de experiências, sejam elas positivas ou negativas. A troca de informações permite que os mesmos erros não sejam cometidos novamente, impulsionando de forma positiva 0 desenvolvimento e expansão do setor no estado e também no Brasil. De acordo com ESCOBAR \& COELHO (2014), o Brasil tem um enorme potencial para o desenvolvimento do mercado de pellets de madeira, principalmente pela demanda térmica do setor comercial e industrial que segundo estimativa preliminar dos autores, poderia ter um mercado de até 21 milhões de toneladas de pellets por ano.

Além disso, depende das empresas produtoras evidenciar as qualidades dos pellets, promovendo o conhecimento por parte da população em geral e futuros usuários deste tipo de energia.

\section{CONCLUSÃO}

A cadeia produtiva de pellets em Santa Catarina é recente.

A matéria-prima utilizada para a produção de pellets é a maravalha de Pinus spp. com baixo teor de umidade e representa a maior parte dos custos de produção.

Os equipamentos para peletização são adaptados para biomassa.

O mercado interno (nacional) absorve toda a produção de pellets catarinense.

Para viabilizar a exportação é necessário se adequar as normas internacionais de qualidade dos pellets e aumentar a escala de produção.

Os consumidores nacionais de pellets não são exigentes em relação às propriedades do produto final e não questionam algum documento que ateste sua qualidade.

A criação de uma normatização brasileira de qualidade dos pellets é fundamental para consolidar o produto nos mercados nacional e internacional.

\section{AGRADECIMENTOS}

À FAPESC (Fundação de Amparo à Pesquisa e Inovação do Estado de Santa Catarina) pelo apoio financeiro ao trabalho, à UDESC (Universidade do Estado de Santa Catarina) pelo auxílio nas pesquisas e ao Conselho Nacional de Desenvolvimento Científico e Tecnológico (CNPq. Projeto 303063 / 2017-3 - PQ 2017).

\section{REFERÊNCIAS}

BATALHA MO \& SILVA ALDA. 2001. Gerenciamento de sistemas agroindustriais: definições e correntes metodológicas. In: BATALHA MO (Coord.). Gestão Agroindustrial. São Paulo: Atlas. p.23-63.

BRAND MA \& COSTA VJ. 2007. Geração de energia: o futuro da biomassa florestal. In: BINOTTO E. Tecnologia e processos agroindustriais. 1.ed. Passo Fundo: UPF. p.141-158.

CALDERON C et al. 2013. Bioenergy outlook. Statistical Report 2013. Brussel: AEBIOM.

CALDERON C et al. 2014. Bioenergy outlook. Statistical Report 2014. Brussel: AEBIOM.

CEN. 2014. European committee for standardization. EN ISO 17225-2:2014 - Solid Solid Biofuels - Fuel Specifications and Classes - Part 2: Graded Wood Pellets. Brussels: European Committee for Standardization.

DIAS JMS et al. 2012. Produção de briquetes e péletes a partir de resíduos agrícolas, agroindustriais e florestais. Brasília: Embrapa Agroenergia.

ESCOBAR JF \& COELHO ST. 2014. O Potencial dos pellets de madeira como energia no Brasil. Jornal Biomassa 3: 914.

GARCIA DP et al. 2017. O setor de pellets de madeira no Brasil. Revista Ciência da Madeira 8: 21-28.

KRISTÖFEL C et al. 2016. The wood pellet market in Austria: A structural market model analysis. Energy Policy 88: 402412.

NIEDZIÓŁKA I. 2015. Assessment of the energetic and mechanical properties of pellets produced from agricultural biomass. Renewable Energy 76: 312-317.

NONES DL et al. 2017. Biomassa residual agrícola e florestal na produção de compactados para geração de energia. Revista de Ciências Agroveterinárias 16: 155-164.

NONES DL. 2014. Cadeia produtiva de pellets e briquetes de biomassa residual para geração de energia em Santa Catarina. Dissertação (Mestrado em Engenharia Florestal) Lages: UDESC. 124p.

SAMPIERI RH et al. 2006. Metodología de la investigación. 5.ed. São Paulo: McGraw-Hill. 624p.

SPANHOL A et al. 2015. Qualidade dos pellets de biomassa florestal produzidos em Santa Catarina para a geração de energia. Floresta 45: 833-844. 